\title{
Volunteer Map Data Collection at the USGS
}

\section{The History of Volunteers and the USGS Mapping Program}

Since 1994, citizen volunteers have helped the U.S. Geological Survey (USGS) improve its topographic maps. Through the Earth Science Corps program, citizens were able to "adopt a quad" and collect new information and update existing map features. Until its conclusion in 2001 , as many as 300 volunteers annotated paper maps which were incorporated into the USGS topographic-map revision process.

\section{The National Map Corps}

The National Map was created in 2001 as a seamless, continuously maintained, nationally consistent set of geographic data. At the same time, the volunteer program was renamed The National Map Corps. The emphasis shifted from annotating printed maps to collecting data using GPS units. Between 2003 and 2006, over 22,000 data points were submitted by over 1,000 volunteers. Data were submitted in various forms, including spreadsheets, emails, and handwritten notes. In 2006, a web-based tool was launched and was used by over 400 volunteers to submit over 3,800 data points. The National Map Corps program was suspended in 2008 due to budget considerations.

\section{The Emergence of Volunteered Geographic Information}

In recent years, new web- and mobile-based technologies have made it easier to create, combine, and share maps. Recent events have shown how well these technologies support the rapid production of geographic information. This technology is commonly employed by community members rather than authoritative or commercial mapping organizations. The term "volunteered geographic information" (VGI) was coined to describe this crowdsourcing of geospatial information. In light of this rapidly changing technical landscape, increasing use of social networking, and mandates for more transparency and citizen involvement in government, the USGS is revitalizing its volunteer program.

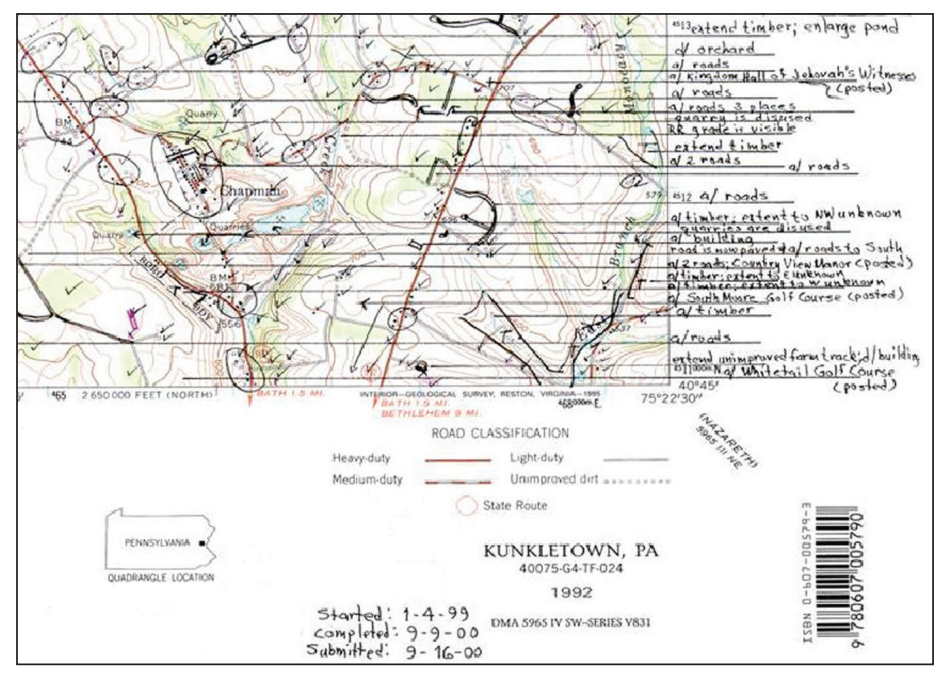

Figure 1. Portion of Kunkletown, PA Quadrangle, hand annotated by volunteer, submitted to USGS in 2000.

\section{Current USGS Efforts to Include VGI}

\section{USGS Workshop on VGI}

The USGS held a workshop on VGI in January 2010. The goal of the workshop was to bring together representatives from various public and private programs that successfully engage volunteers to collect data. The workshop included people from the National Oceanic and Atmospheric Administration's Cooperative Observer Program, the Library of Congress (with its online crowdsourced identification of historic photographs), the WikiMedia Foundation, and OpenStreetMap (OSM, the non-profit venture to build an online map of the world through volunteered effort). The collaboration in the workshop raised a number of questions that need to be explored to help the USGS establish a viable volunteer program. These included:

- Can VGI integrate with authoritative data?

- What is the quality of VGI?

- What data types are suited for volunteer collection?

- How can volunteers be motivated and encouraged?

- What are the costs and benefits of VGI compared to standard data collection methods?

- How sustainable is VGI?

\section{OpenStreetMap Collaborative Project, Phase One}

The USGS initiated an experimental project, the OpenStreetMap Collaborative Prototype (OSMCP), to explore some of the questions from the workshop. Phase One of OSMCP evaluated different VGI platforms, such as the web-based collection tool used previously by The National Map Corps and the software used to make contributions to the National Hydrography Dataset. Ultimately, the open-source software from OSM was setup on an internet server hosted in the usgs.gov domain.

The OSM software had many positive attributes:

- Purpose-built for collecting VGI.

- Provides easy browser-based editing.

- Data scheme can be customized.

- Has no software-license cost for users or the USGS.

- Has minimal system requirements, which allowed reuse of existing USGS hardware.

- Support available through the OSM community.

In Phase One, the USGS partnered with the Data Access and Support Center (DASC) of Kansas. To evaluate the prototype platform, road data provided by DASC was edited to meet USGS specifications for accuracy, completeness, and conformance. Data were edited simultaneously by DASC staff members in Kansas and USGS staff members in Colorado. The edits focused on Douglas and Johnson counties in Kansas. 


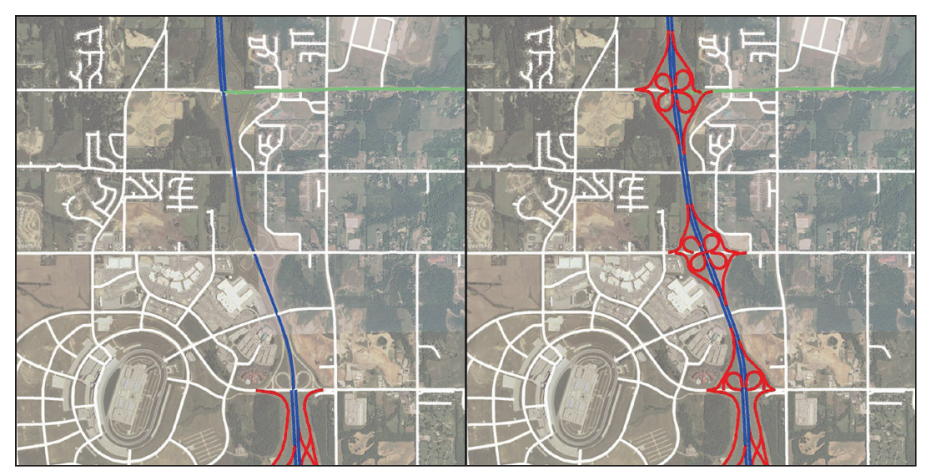

Figure 2. Example of Phase One results. Unedited highway intersection, left. Corrected intersection with access ramps, right.

Data editors were provided with detailed instructions based on USGS data standards. All data editing used heads-up digitizing over The National Map orthoimagery layer in the OSM Potlatch browser-based editing software. Interstate highways, U.S. routes, ramps, and service roads were edited by USGS staff. State routes were edited by DASC staff.

At the completion of Phase One, the edited roads for the two Kansas counties met quality requirements for both The National Map and the State of Kansas. This phase demonstrated how geographically distributed users could improve data by adding missing interchanges, divided highways, and attributes. The OSM software proved to be easy to use for collaborative editing. Phase One is described in greater detail in the USGS Open File Report "OpenStreetMap Collaborative Prototype, Phase One," by Eric B. Wolf and others (2011). This report is available online at pubs.usgs.gov/ of $/ 2011 / 1136$.

\section{OSMCP Phase Two}

In Phase Two, the USGS worked with students from the University of Denver and the University of Colorado at Denver. Data for thirty types of structures were systematically collected by the student volunteers for the four 7.5-minute USGS topographic quadrangles containing most of the Denver urban area. The goal of this phase was to better understand the costs and benefits of volunteered data collection relative to data-collection methods normally used at the USGS.

Phase Two used the OSM Potlatch 2 editor. The volunteers used tags to collect the structure attributes required by The National Map. Tagging was used to manage a quality control process within the OSMCP. In addition to the orthoimagery layer from The National Map, background layers were provided from The National Map basemap and digital raster graphics (DRG, scanned 7.5 minute topographic maps) to locate structures.

In order to provide cost-effective quality control of VGI, the USGS needs to use "volunteer editors," such as those used by Wikipedia. com. To understand how well volunteers could check VGI, every data point in the four quads was verified both by volunteers and USGS staff. Phase Two also provided the USGS with valuable feedback on the usability of the OSMCP interface by volunteers. A report on the second phase of the project will be made available online pending internal review.

\section{The Future of The National Map Corps}

Phase One of this initiative demonstrated the capabilities of the OSM software as a platform for VGI programs at the USGS. Phase Two demonstrated that a volunteer process can be used to create authoritative data for The National Map. A third phase is planned to

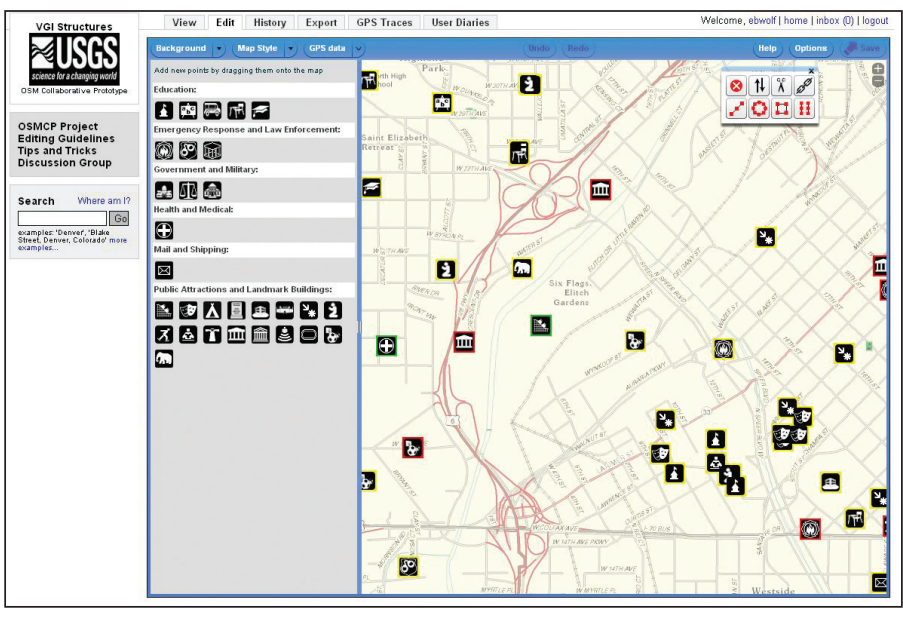

Figure 3. The Potlatch 2 editor used in Phase Two showing symbols created for the OSMCP project overlaid on cartographic tiles from The National Map.

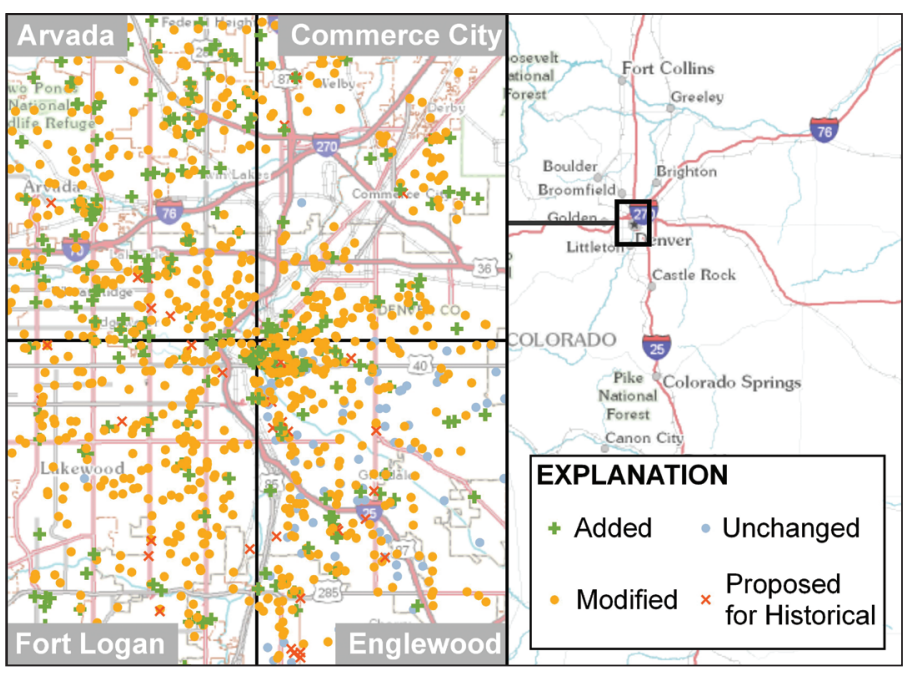

Figure 4. The data representing several hundred structures in the four quadrangles were added, edited, or marked "Proposed for Historical" classification by the volunteers during Phase Two.

begin in late 2011 which will expand volunteer collection of structures data to the entire state of Colorado. The collection process will be simplified through the application of user-centered design principles. A wide range of volunteer groups will be engaged, possibly including state and local government partners, schools, community groups, and individual contributors. If the data-collection methods prove cost-effective, the program may be expanded nationwide. The new data-collection methods actively engage citizens and reflect the principles of transparency, participation, and collaboration set forth in President Obama's Memorandum on Transparency and Open Government, issued on January 21, 2009.

\section{For more information:}

The National Map, nationalmap.gov

OpenStreetMap Collaborative Prototype, navigator.er.usgs.gov

Kansas DASC, www.kansasgis.org

National Council on Geographic Education, www.ncge.org

National Aerial Imagery Program, go.usa.gov/BRj

USGS Workshop on Volunteered Geographic Information,

cegis.usgs.gov/vgi

USGS Open File Report "OpenStreetMap Collaborative

Prototype, Phase One,” pubs.usgs.gov/of/2011/1136 